\title{
Effect of Short Time Exposure to Pesticides on the Respiratory Function of the Cotton Farmers in Banikoara, Benin
}

\author{
Antoine Vikkey Hinson ${ }^{1, *}$, Hervé Lawin ${ }^{1}$, Menonli Adjobimey ${ }^{1,2}$, Edorh Gbéhomilo ${ }^{3}$, Tadégla \\ Danha $^{1}$, Rose Mikponhoué $^{1}$ \\ 1: Unit of Teaching and Research in Occupational Health and Environment, Faculty of sciences and health of \\ Cotonou (University of Abomey-Calavi, Benin), 01 PO 188 Cotonou, Benin \\ 2: Service de santé au travail du Centre National Hospitalier Universitaire de Pneumo-Phtisiologie de Cotonou \\ (CNHU-PPC), Bénin, 01 BP 321 Cotonou, Benin \\ 3:Service de Médecine du Travail, Centre Hospitalier Universitaire Sylvanus Olympio, Lomé (Togo) \\ *Corresponding Author: Antoine Vikkey HINSON, Unit of Teaching and Research in Occupational \\ Health and Environment, Faculty of sciences and health of Cotonou (University of Abomey-Calavi, \\ Benin), 01 PO 188 Cotonou, Benin. Email: hinsvikkey@yahoo.fr
}

\begin{abstract}
Objective: Evaluate the effect of organophosphorus pesticides on the respiratory function of Banikoara cotton farmers.

Methods: It was a cross-sectional study that allowed us to select non-probabilistically 43 producers using pesticides. They were submitted to a questionnaire, acetyl-cholinesterase (AChE) dosages and spirometry test. The collected data were analysed using the Epi Info .7 software. Univariate analysis was done to describe frequencies and averages. The Student's t-test was used to compare the AChE averages and the spirometry indicators during the bivariate analysis. A Linear regression was used to investigate the relationship between exposure level and respiratory function by adjusting confounders.

Results: Most of the pesticides identified are organophosphates compounds or combinations with pyrethroids and sometimes organochlorines. The study population had an average age of $34.4 \pm 7.8$ years and more than half were uneducated. There was a significant decrease in AChE of $3.02 \pm 2.3 \mathrm{U} / \mathrm{gHb}$ when spraying pesticides by $15 \%$ compared to pre-exposure. Also, there is a significant decrease in mean forced expiratory volume per second (FEVI) of $330 \mathrm{ml}$ when spraying pesticides.A decrease in the AChE level of $1 \mathrm{U} / \mathrm{g} \mathrm{Hb}$ results in a significant $72 \mathrm{ml}$ decrease in $F E V I, I C_{95 \%}[0.01,0.22]$.
\end{abstract}

Conclusions: The use of pesticides significantly reduces respiratory function, including FEV1 although the inhibition of AChE has not reached WHO threshold value.

Keywords: Pesticides, Acetylcholinesterase, Respiratory disorders, FEVI, Benin

\section{INTRODUCTION}

According to the United Nations Food and Agriculture Organization (FAO), "a pesticide is any substance or mixture of substances used to neutralize or destroy a pest, a vector of human or animal disease, a plant or animal species harmful during the production, processing, preservation or storage of agricultural products'[1].The widespread and dangerous use of pesticides creates major risks for both human health and the environment.According to the World Health Organization (WHO), every year, one million people are accidentally poisoned with pesticides in the world and 20,000 are killed. If we add the intentional cases, then we can reach 3 million cases of poisoning, among which there are 200,000 deaths.Developing countries use $20 \%$ of pesticides but account for 99\% of cases of poisoning[2]. The massive and widespread use of OP pesticides, coupled with the presence or absence of adequate education and regulatory measures, raises concerns about their impact on the environment and especially on health [3]. The hazards related to pesticides affect millions of exposed occupations. The main occupations concerned are farmers, gardeners, winemakers, market gardeners. Foresters, forest products manufacturing workers, road safety and building workers are 
also very exposed [4]. Because the lung constitutes the target organ of all inhaled toxic substances, it is reasonable to assume that the function of this organ would be affected through exposure to pesticides via inhalation a major route of pesticide penetration [5]. Pesticide spraying agents, therefore, represent a particular predisposed target, because their job leads them to the widespread and dangerous use of pesticides. They are near the source of the pollution (preparation of pesticides) and they are also in the middle of the pollution (use of the spraying devices) for hours [6].

According to the National Institute for Research and Safety (INRS), occupational respiratory diseases due to insecticides are poorly studied and their frequency is unknown if we exclude respiratory symptoms in the context of systemic poisoning[7].In addition to accidental exposures, there is an association between respiratory symptoms, asthma and the use of anticholinesterase and organophosphorus carbamates based on recent studies conducted in agricultural settings [8-10]. On the other hand, some studies have shown an association between obstructive pulmonary disease and exposure to OP pesticides[11-13].Chakraborty, Huang et al. also found a relationship between exposure to the cholinesterase pesticides of spraying agricultural agents and lung respiratory function with impaired FEV1 and FEV1 / FVC ratio in the group of exposed people [14,15]. Conversely, Jones et al. found no respiratory function impairment by comparing a group of exposed people with a group of unexposed people before and after an aerial campaign of organophosphorus and anticholinesterase carbamates[16].

The main findings of the studies mentioned in the previous paragraph show the evaluation of respiratory symptoms and pulmonary function during chronic exposure to organophosphorus pesticides. In Benin, many studies have been done on cases of acute pesticide poisoning $[17,18,3]$. Some have focused on the determination of cholinesterase including those of Hinson[19] and Loko [20]; others on comparing the biological values of cotton farmers before and after exposure[2] and [21]. But in our case, the effect on pulmonary function during acute exposure to organophosphorus pesticides has not been evaluated. This is the reason for the choice of this study entitled "Effect of short time exposure to organophosphorus pesticides on respiratory function of the cotton farmers in Banikoara (North Benin)".

\section{MeTHODS}

It is a descriptive and analytical cross-sectional study that took place from $15^{\text {th }}$ July, 2017 to $20^{\text {th }}$ August, 2017 at Banikoara, one of the biggest municipalities of cotton production in Benin.The study population consists of organophosphorus pesticide spraying agents from the cotton fields.

By an exhaustive sampling of all pesticidesprayers, we recruited 43 cotton farmers who met the following criteria:Living in the commune of Banikoara, spray their fields with organophosphorus pesticides and gave their informed consent. These 43 pesticide sprayers were submitted to a questionnaire followed by the determination of the level acetylcholinesterase (AChE) and cotton grower's respiratory function'sindicators during a spray session. For the AChE test, each individual is taken as his witness. The questionnaire was administered to 43 cotton farmers face-to-face by trained officers in local languages or French. The questionnaire variables were:

\subsection{Dependent Variable}

The dependent variable here deals with the respiratory function of cotton farmers during a spray session.

The electronic spirometer Microlab Spirometer type (MicroMedical, UK) regularly calibrated, is used following the protocol; the spirometry test followed the ATS / ERS 2005 standard andmeasured the following volumes:

FEV1: Forced Expiratory Volume in 1 second; it is the maximum volume of exhaled air blown out during the first second of exhalation as complete as possible following a deep inhalation.

FVC: Forced Vital Capacity. The vital capacity is the maximum volume of air that can be mobilized between full inspiration and expiration.

FEV1 / FVC: The FEV1 / FVC ratio represents the TIFFENEAU ratio needed for confirmation of an obstructive airway disorder.

PEFR: Peak Expiratory Flow Rate; it is the maximum flow rate obtained during forced expiration. 


\subsection{Independents variables}

They are:

Kind of pesticides used and the application program

Socio-demographic variables: Age, height, weight, sex, marital status and level of education

Occupational variables: the volume of pesticides used, length of the spraying job, the area sprayed and the last spraying session.

Variables relating to knowledge, attitudes and practices of the use of OP pesticides:pesticides hazardous for spraying agents, pesticides hazardous for non-spraying agents living in the field, pesticides penetrating the body through contact on healthy skin, headaches after normal spraying, information and training on protection during spray sessions, pesticides hazardous for people living near the fields, pictograms on bottles of pesticides, practice of regular medical examinations for spraying agents, use of protective equipment when spraying the fields, disposal of empty pesticides containers, taking bath systematically after spraying, precautions after spraying.

\subsection{Variables relating to the level of $\mathrm{AChE}$ activity}

The activity of Erythrocyte Acetylcholinesterase (AChE) was measured by the modified ELLMAN colorimetric method using a standardized device approved by the WHO: Test-mate ${ }^{\circledR}$ apparatus (System model 400): it is a spectrophotometer which is a photometric analyser calibrated at $25^{\circ} \mathrm{C}$. The measurement was related to the level of haemoglobin also given by the apparatus, thus giving a unit of measurement in units per gram of haemoglobin $(\mathrm{U} / \mathrm{g}$ of $\mathrm{Hb})[22]$.

\subsection{Measurement of pulmonary function}

The respiratory functional explorations were carried out by two health workers trained for spirometry. To control the circadian variation of pulmonary function the spirograms were performed between 11:00 to 15:00. For each subject, the procedure was repeated three times and the best manoeuvre accepted. We selected the best value each time taking into account the participant's cooperation and the aspect of the flow-volume curve. All the results of the 43 participants were reviewed by an independent specialist (pneumologist) skilled in spirometry. He rigorously retained 39 spirograms of good quality.

\subsection{Measurement of Erythrocyte Acetyl- cholinesterase activity (AChE)}

The determination of the erythrocyte acetylcholinesterase level wascarried out by a laboratory technician trained to handle the apparatus. The data collection form is numbered from 1 to 43. Each individual has a form number corresponding to his serial number. This measurement of the activity of cholinesterase is made during the rest period. The blood sample was taken at the fingertip and collected in the tube. The test of the subjects was done in the morning or the rainy season when the temperature is lower than $25^{\circ} \mathrm{C}$ in the shade. When the conditions are not good enough the device stops automatically. The results of the device are also displayed automatically. To measure the activity of $\mathrm{AChE}, 42$ respondents answered.

The formula used for each individual to have the difference and percentage of inhibition of cholinesterase is as follows:

Inhibition rate $=[(\mathrm{AChE}$ before $-\mathrm{AChE}$ after)/AChE before] x 100

AChE before: individual basic level; AChE after: AChE after exposure to OPs. [23]

Spirometry and erythrocyte acetylcholinesterase measurements were performed in two steps:

The first step is before contact with organophosphorus pesticides: That is preexposure.

Second step: It is thirty-three days after the first step. The second test is done two to five days after the farmers had handled OP pesticides: That is post-exposure.

The period of time usually required is 30 days from the grower's non-exposure to a cholinesterase inhibitor[23].

\subsection{Data Analysis}

The collected data were captured and analysed using the Epi Info7.0 software. The analysis of the data used is univariate to describe frequencies and averages. Student's tests were used to compare $\mathrm{AChE}$ averages and spirometry indicators in bivariate analysis.

Linear regression is used to look for the link between the level of exposure and the respiratory function by adjusting for confusion factors such as age, height, volume of pesticides used, length in the job and level of education. The significance level was $\mathrm{p} \leq 0.05$. 
Effect of Short Time Exposure to Pesticides on the Respiratory Function of the Cotton Farmers in Banikoara, Benin

\section{RESULTS}

\subsection{Socio-demographics and occupational characteristics}

The study population had an average age of 34 and more than half were not educated. They had average professional seniority of 18 years. Table 1

Table 1. Socio-demographics characteristics

\begin{tabular}{|l|c|}
\hline \multicolumn{1}{|c|}{$\begin{array}{c}\text { Socio-demographics } \\
\text { characteristics }\end{array}$} & \\
\hline Age (year)* & $34.4 \pm 7.8$ \\
\hline Weight (Kg)* & $42.2 \pm 8.4$ \\
\hline Height (m) $*$ & $1.7 \pm 0.7$ \\
\hline Matrimonial status n (\%) & \\
\hline Married & $35(81.4 \%)$ \\
\hline Unmarried (Singleor widower) & $8(18.6 \%)$ \\
\hline Level of instruction n(\%) & \\
\hline Any & $25(58.1 \%)$ \\
\hline Primary & $12(27.9 \%)$ \\
\hline Secondary & $6(14 \%)$ \\
\hline Work experience (years) & $17,7 \pm 8.2$ \\
\hline
\end{tabular}

\subsection{Characteristics of pesticide OP} knowledge, attitudes and practices (KAP)

Overall, cotton farmers have poor attitudes and practical knowledge of pesticides, although almost $70 \%$ reported having received training on pesticide use, but continue to adopt risk attitudes (Figure 1).

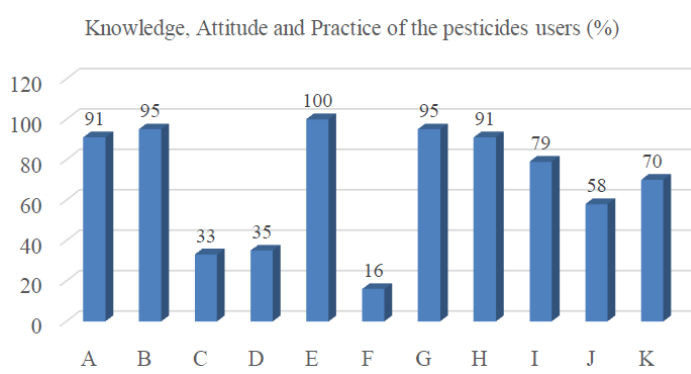

$A=$ Pesticides hazards for people living neara field, $B=$ Have seenthesepictograms once in the bottle, $C=U s e$ of protective equipment when mixing pesticide, $D=U$ se of Protective equipment when spraying pesticide, E=Pesticide harzards during spraying, $F=U$ se of an empty pesticide container for household use, $G=$ Intake pesticide into the body and healthy skin, H=Pesticidehazards for all fieldsworkers, $\quad I=$ For $\quad$ cottonfarmers, havingheadacheseems normal afterspraying, $J=$ Always showerafterspraying, $K=$ Pesticide use training

\subsection{Change in mean AChE level and} respiratory function indicators

There is a significant decrease in AChE level: $3.02 \pm 2.3 \mathrm{U} / \mathrm{gHb}$ during pesticide spraying. This corresponds to an average decrease of $15 \%$ compared to the average of the pre-exposure measurement.Also, there is a significant decrease in the FEV1 mean of $330 \mathrm{ml}$ when spraying pesticides.Although the other parameters of respiratory function have decreased, the difference was not statistically significant: Table 2.

Table 2. Change of AChE mean and respiratory function indicators

\begin{tabular}{|c|c|c|c|c|}
\hline & \multicolumn{3}{|l|}{ Mean \pm SD } & \\
\hline & During spray (DS) & Off spraying(OS) & Difference(DS-OS) & $\begin{array}{l}* \mathrm{CI} 95 \% \text { of } \\
\text { difference }\end{array}$ \\
\hline AChE level (U/g Hb) $(n=42)$ & $17.96 \pm 4.09$ & $20.98 \pm 4.10$ & $-3.02 \pm 2.3$ & {$[-4.67 .-1.37]$} \\
\hline FEV1 (L) $(\mathbf{n}=39)$ & $2.85 \pm 0.68$ & $3.18 \pm 0.60$ & $-0.33 \pm 0.60$ & {$[-0.52 .-0.13]$} \\
\hline FVC (L) $(n=39)$ & $4.00 \pm 0.61$ & $4.05 \pm 0.62$ & $-0.05 \pm 0.43$ & {$\left[\begin{array}{ll}-0.19 . & 0.08\end{array}\right]$} \\
\hline FEV1/FVC (\%)(n=39) & $0.72 \pm 0.17$ & $0.79 \pm 0.14$ & $-0.07 \pm 0.13$ & {$[-0.11 .-0.02]$} \\
\hline FEF (L/S) $(n=39)$ & $3.19 \pm 1.50$ & $5.56 \pm 14.62$ & $-2.36 \pm 1.44$ & {$\left[\begin{array}{lll}-7.05 . & 2.31]\end{array}\right.$} \\
\hline PEF (L/S) $(n=39)$ & $4.29 \pm 1.85$ & $4.67 \pm 1.85$ & $-0.38 \pm 1.44$ & {$\left[\begin{array}{ll}-0.84 . & 0.08\end{array}\right]$} \\
\hline
\end{tabular}

*CI(Confidence Interval)

Variation in maximum expiratory volume per second as a function of the variation in $\mathrm{AChE}$ A decrease in the $\mathrm{AChE}$ rate of $1 \mathrm{U} / \mathrm{gHb}$ results

Table 3. FEVI variation depending on the AChE variation: Multivariate linear regression analysis

\begin{tabular}{|l|l|l|l|}
\hline & \multicolumn{3}{|c|}{ FEV1 Variation (L) } \\
\hline & \multicolumn{1}{|c|}{ Crude Coefficient } & \multicolumn{1}{c|}{ Adjusted Coefficient } & \multicolumn{1}{c|}{ CI 95\% } \\
\hline Variation of AChE level (U/gHb) & 0.046 & 0.072 & {$[0.01,0.22]$} \\
\hline Age (years) & & -0.002 & {$[-0.12,0.23]$} \\
\hline Height (m) & & -0.10 & {$[-0.18,0.39]$} \\
\hline Pesticide volume used(L) & & 0.01 & {$[-0.02,0.12]$} \\
\hline Work experience (years) & & 0.08 & {$[-0.09,0.13]$} \\
\hline Level of education & & 0.03 & {$[-0.04,0.43]$} \\
\hline
\end{tabular}




\section{Discussion}

\subsection{Socio-demographic and occupational characteristics}

The average age of cotton farmers is 34 years. This shows that the population of Banikoara cotton farmers who participated in the study is young. This result is close to the one by Hinson found in Gogounou (North Benin) in 2014 and which is 32 years [21]. Also, more than half of Banikoara's cotton farmers were uneducated. This could be an obstacle to proper identification and handling of pesticides. In Hinson's study conducted in the same city in 2012, the majority of respondents are illiterate $(80.3 \%)$ [3]. In contrast, in the United States, more than half of pesticide users had at least 12 years of schooling [24].

The cotton farmers had an average of 18 years of occupational service and had practiced spraying in the majority between 3 and $15 \mathrm{~L}$ over an area that usually ranged from 2 to 8 hectares. The study by Chakraborty et al. in India found that exposure to organophosphorus pesticides from agricultural spraying agents averaged 14 years [14].

\subsection{Types of pesticides used by cotton farmers in the municipality study (Banikoara) in 2016}

The chemical pesticides used are mainly organophosphorus compounds, pyrethroids or combinations of pyrethroids and organophosphorus compounds and some organochlorines. But those listed pesticides correspond to the official formulations delivered by the CARDER.

Note that this list of pesticides does not take into account those of the informal circuit that cotton farmers are wary of declaring given the delicacy of the issue of agricultural inputs.

Also, the listed pesticides are WHO Class II (moderately hazardous) or Class III (slightly hazardous). According to the Institute of Geography and Statistics of Brazil in 2006, the registered pesticides were WHO Class I (Ia: extremely hazardous and $\mathrm{Ib}$ : very hazardous [25]. The study by Hinson et al.[21]also listed class II pesticides in Gogounou in 2012.

\subsection{Knowledge, attitudes and practices on $O P$ pesticides}

The assessment of pesticide knowledge revealed that $100 \%$ and $90.7 \%$ of cotton farmers, respectively, report that pesticides are hazardous when spraying and also for the population living near fields. These results confirm the one by Lawin (2013) obtained from 36 market gardeners in Benin, which show, on the one hand, that the majority had knowledge of the hazardousness of pesticides for the spraying agents and for the consumer and, on the other hand, only $25 \%$ of them are aware of the neighbourhood pollution that can be induced by pesticides [2]. This result is also confirmed by a South African study[26]which showed a good knowledge of the influence of environmental exposure to pesticides on neighbours within a radius of $10 \mathrm{~km}$. Also, in this study, $95 \%$ of cotton farmers state that they have already seen the pictograms once on the bottles and among them, three-fourths do not feel they know the meanings. This is consistent with a study conducted in Brazil (2007) showing the farmers' very little knowledge of pictograms[27].The reasons given in this study are: the high technicality of the figures, the low illegibility of the safety instructions and the illiteracy of the users. Another study conducted by Passiani in Brazil in 2012 [26, 28] found that $68.8 \%$ of respondents knew the meaning of the icons on the labelling.

As for attitudes and practices, the majority of the cotton farmers in the study contribute to the pollution of the fields and the environment by either abandoning empty pesticide bottles on the site or burning them or burying them in the soil. $16 \%$ continue to use empty containers of pesticides for household purposes. This practice is very hazardous, and often is a source of domestic poisoning with plant protection products. Reuse for household purposes and the sale of empty containers are mentioned more in the Hinson and Lawin's studies in Benin [3, 2]. In Mali, it is the practice of incineration which comes first with $62 \%$ andin Senegal, it is abandonment in the fields for $70 \%$ of respondents [29].

As for personal protective equipment, they are rarely used by cotton farmers during preparation or spraying. And yet PPE has been a major contributor to reducing pesticide exposure. This attitude of cotton farmers is also found in Hinson's study in 2013 with more than twothirds of respondents stating that they took no precautionary measures before handling pesticides [3].

Given all those results on KAPs, we can say that cotton farmers adopt poor behaviours 
concerning the use of pesticides, although almost $70 \%$ reported having received training on the use of pesticides. This finding is consistent with the one by Ospina JM et al[30, 27] who said that pesticide education sessions among users improve their knowledge but have very little impact on their attitudes and practices. There is, therefore, a need for monitoring in the practical use of pesticides because the quantities of pesticides handled by farmers are not negligible. Generally, cottonfarmers use between 3 to 15 litres of pesticides, which are mostly OPs and / or pyrethroids classified in WHO category II and III.

\subsection{Variation in average $\mathrm{AChE}$ levels and effects on respiratory function}

In this study of cotton-farmers free from known lung diseases and non-smokers, we found that the spraying of OP pesticides resulted in a significant reduction in the mean of $\mathrm{AChE}$ level: $3.02 \pm 2.3 \mathrm{U} / \mathrm{g}$ of $\mathrm{Hb}$. This inhibition of the level of erythrocyte acetyl-cholinesterase corresponds to an average decrease of $15 \%$ compared to the mean of the pre-exposure measurement. This value does not require any eviction measure according to the WHO standards because it is less than $30 \%$, which is the limit value compared to the pre-exposure measurement recommended by the WHO[1].

Nevertheless, this average decrease of $15 \%$ resulted in a significant decrease in the Forced Expiratory Volume per Second (FEV1) of 330 $\mathrm{ml}$ when spraying pesticides. Huang et al[15] found in 1995 an alteration of FEV1 in the group of chlorothalonil workers compared to unexposed people. In 2009 Chakraborty et al[14]found values close to the ones in this study with a significant reduction in FEV1 of $420 \mathrm{ml}$ in agricultural agents in India who had a $34.2 \%$ decrease in cholinesterase activity.

After a multivariate linear regression analysis of the FEV1 change, we found that there was a significant $72 \mathrm{ml}$ decrease in FEV1 by $1 \mathrm{U} / \mathrm{g}$ of $\mathrm{Hb}$ reduction in cholinesterase activity. This analysis doesn't only take into account the confounding factors but also the volume of pesticide used by cotton farmers even though we could not tell the exact volume of OP pesticides. The amount of pesticide used is not often reported in studies looking at the links between pesticide exposure and respiratory health. Chakraborty et al[14]found a Spearman correlation coefficient of 0.64 between FEV1 and acetyl-cholinesterase levels.

Conversely, other studies found no significant differences in lung function between exposure to OPs and control groups. Jones et al. [16], in 2003, did not find an excess of asthma symptoms or respiratory function changes by comparing a group of Arkansas to a group of unexposed people living in the same area, before and after an aerial application campaign of herbicides and insecticides comprising various organophosphorus compounds, anticholinesterase carbamates and synthetic pyrethroids. A large number of losses in followup in this study may explain the difference in conclusion with our study.Also, the spraying mode used (spreading with planes) seems to expose workers less to the spraying conditions we found with Banikoara cotton farmers. Garnier et al in 2003[31] and Hoppin et al in 2006 [32] examined workers exposed to paraquat and pulmonary function without being able to show any significant differences in lung function among study populations of agricultural workers. The role of other coexposure in those populations of agricultural workers also subject to irritants (biocides, mineral dusts) or allergens (pollens, animal dander ...) could also explain this contradiction with our results.

In general, those contradictory results to ours could also be explained by the environmental exposure to pesticides which makes that the groups of unexposed people chosen in some studies are also exposed indirectly, thus creating classification biases. Indeed, there is environmental exposure to pesticides within a radius of $10 \mathrm{~km}$ around fields according to a South African study [26]. That's why we used the spraying agent as his witness in our work. Besides, not excluding participants with a history of lung disease may also obscure the relationship between exposure to OPs and lung function.

\section{CONCLUSION}

Cotton farmers have a poor practical attitude towards the use of pesticides, although they have a fairly good knowledge of the dangerousness of pesticides. Also for the first time in Benin even in Africa, it has been shown that the use of these pesticides significantly reduces respiratory function including FEV1 although the inhibition of Ache has not reached 
the WHO threshold value. There is therefore a need to take preventive measures.

\section{ACKNOWLEDGEMENT}

We thanks all the cotton farmers for their participation

\section{REFERENCES}

[1] PNUE, FAO, OMS. Elimination de grande quantité de pesticides périmés dans les pays en développement; 1996, page 96.

[2] Lawin H. Evaluation de l'impact des interventions en Ecosanté sur le risque d'intoxication aux pesticides des maraîchers de Houéyiho , Mémoire diplôme d'études spécialisées en santé au travail et environnement;(FSS/URESTE) Cotonou, 2013; p2-5.

[3] Hinson A;V. Lawin H. Gounongbe F. Dossou F. Fayomi B. Knowledge, Attitudes, Practices of farmers exposed to pesticides at Banikoara Township (Republic of Benin). J Environ Health Sci. 2015, 1(2) 1-5

[4] Les principales situations professionnelles à risques des pesticides. Consulted the17th August 2019 [Internet]. Available on: http://www.officiel-prevention.com/ protection ns-collectives-organisation-ergonomie/risquechimique/detail_dossier_CHSCT

[5] Dowling K.C., Seiber J.N. Importance of respiratory exposure to pesticides among agricultural populations. Int J Toxicol 2002; 21:371-81.

[6] Kummer R., van Sittert N.J. Field studies on health effects from the application of two organophosphorus insecticide formulations by hand-held ULV to cotton. Toxicol Lett 1986 Oct;33(1-3):7-24

[7] INRS: Allergie respiratoire professionnelle aux produits phytosanitaires; Fiche d'allergologiepneumologie professionnelle;TR 50, amt, Document pour le Médecin du Travail $\mathrm{N}^{\circ} 124$, 4èmetrimestre 2010, p471. Consulted 29th Jully 2019on http://www.inrs.fr/.

[8] Bessot J.C., Blaumeisser M., Kopferschmitt M.C., Pauli G. L'asthme professionnel en milieu agricole. Rev Mal Resp, 1996, 13 : 205 215.

[9] Chan-yeung M., Enarson D.A., Kennedy S.M. The impact of grain dust on respiratory health. Am Rev Respir Dis, 1992, 145 : 476-487.

[10] Senthilsevan A., Mc Duffie H.H., Dosman J.A. Association of asthma with use of pesticides. Results off a cross-sectional survey of farmers. Am Rev Respir Dis, 1992; 146 (4):884-87.

[11] Doust E., Ayres J.G., Devereux G., Dick F., Crawford J. O, Cowin H.,Dixon K. Is pesticide exposure a cause of obstructive airways disease? Eur Respir Rev Off J Eur Respir Soc. juin 2014;23(132):180-92.

[12] Hoppin J.A., Valcin M., Henneberger P.K., Kullman G.J., Umbach D.M., Alavanja M.C.R., et al. Pesticide use and chronic bronchitis among farmers in the Agricultural Health Study. Am J Ind Med. déc 2007;50(12):969-79.

[13] Faria N.M.X., Facchini L.A., Fassa A.G., Tomasi E. Pesticides and respiratory symptoms among farmers. Rev Saúde Pública. dec 2005;39(6):973-81.

[14] Chakraborty S., Mukherjee S., Roychoudhury S., Siddique S., Lahiri T., Ray M.R. Chronic exposures to cholinesterase-inhibiting pesticides adversely affect respiratory health of agricultural workers in India. J Occup Health. 2009;51(6):488-97.

[15] Huang J., Aoyama K., Ueda A., Matsushita T. Respiratory effects and skin allergy in workers exposed to tetrachloroisophthalonitrile. Bull Environ Contam Toxicol. août 1995;55 (2):320 -4 .

[16] Jones S.M, Burks A.W, Spencer H.J, Lensing S et Al. Occupational asthma symptoms and respiratory function among aerial pesticides applicators. Am J Ind Med. 2003: 43 (4) : 40717.

[17] Alapini B.I.F. Les intoxications aigues collectives en zone de culture du coton au Bénin: Aspects toxicologiques, étiologiques et stratégies de lutte. Thèse de médecine 2003, p70. [Cotonou]: FSS/UAC;

[18] Akotan M.A. Les intoxications aigues collectives aux pesticides chez les enfants dans le département du Borgou au Bénin: Données épidémiologique et écosystème de 2010 à 2011 ;UAC/FSS Cotonou, 2011.p70.

[19] Hinson A.V, Dédjan H. Fayomi B.E. Biomarkers, clinical and behaviours indicators of pesticide exposure at community level.Afr Newslett on Occup Health and Safety 2007: 17 14-16

[20] Loko F., Amouzou E.K., Yovo K.S., Adjoko N., Gandonou N., Zohoun I. Détermination des activités acétylcholinestérases et butylcholinestérases sanguines de base chez les travailleurs agricoles en milieu cotonnier au Bénin. Journal des sciences. 2007 volume 7(1);21-24.

[21] Hinson A.V., Mama C.I., Lawin H., Dossou F., Gounongbé F., Ayelo P., et al. Evaluation des indicateurs biologiques d'exposition aux pesticides organophosphorés et la fonction hépatique des agriculteurs de la commune de Gogounou au nord-est du Benin Journal de la Société de Biologie Clinique du Bénin, 2016; $\mathrm{N}^{\circ} 024 ; 9-14 \mathrm{t}$ 
[22] EQM Research. Test-mate ChE Cholinesterase Test System (Model 400). Cincinnati, OH: EQM Research; 1-31; 2003.www.eqmres earch .com/Manual-E.pdf, consultedthe 13th May 2019.

[23] Mamadou A., Doumma A., Mazih A., Coulibaly B.M. Exportation aux organophosphorés en milieu rural nigérien: étude de l'activité enzymatique érythrocytaire des cholinestérases comme indicateur biologique. vertigO-la revue électronique en sciences de l'environnement Décembre 2008; 8(3): p5.Consultedthe 23th March 2016.

[24] Stokes L., Starks A., Marshall E., Narang A. Neurotoxcyty among pesticide applicator exposed to organophosphates.Occup. Environ. Med 1995,52: 648-653.

[25] Brazilian institute of Geography and statistics. Censo Agropécuario 2006. Consultedthe 25 August 2019 [Internet]. Available on: http:/www.sidra.gov.br

[26] Dalvie M.A., London L. The impact of aerial application of organophosphates on the cholinesterase levels of rural residents in the Vaalharts district, Northern Cape Province, South Africa. Environmental Research. 2006; 120:326-32.
[27] Waichman A.V., Eve E., Nina N.C.D.S. Do farmers understand the information displayed on pesticide product labels? A key question to reduce pesticides expuse and rish of poisoning in the Brazilian Amazon. Crop Protection 2007;26: 576-83.

[28] Passiani J.O., Torres P., Silva J.R., Diniz B.G., Caldas E.D. Attitudes and Pratiques and Biomonitoring and farmers and Residents Exposed to Pesticides in Brazil. Int.J. Environ; res. public Health 2012,9:3051-3068.

[29] PAN-Afica: Rapport d'étude sur les pesticides dangereux au Bénin 2004,(PAN-Africa :2004); 2, 87p.

[30] Ospina J., Manrique -Abril F., Ariza N. Educational interventions in pesticides use. Rev Salud Publica (Bogota).Mar-Apr 2009; 11(2):182-90.

[31] Garnier R., Bazire A., Chataigner D. Effets sur la santé de l'utilisation professionnelle du paraquat. Arch Mal Prof. 2003; 64 (5): 310-24.

[32] Hoppin JA, Umbach DM, London SJ, Lynch CF, Alavanja MCR, Sandler DP. Pesticides and adult respiratory outcomes in the agricultural health study. Ann N Y Acad Sci. sept 2006;1076:343-54.

Citation: Antoine Vikkey Hinson et al, Effect of Short Time Exposure to Pesticides on the Respiratory Function of the Cotton Farmers in Banikoara, Benin. ARC Journal of Public Health and Community Medicine. 2020; 5(1):22-29. DOI: dx.doi. org /10.20431/2456-0596.0501005.

Copyright: (C) 2020 Authors. This is an open-access article distributed under the terms of the Creative Commons Attribution License, which permits unrestricted use, distribution, and reproduction in any medium, provided the original author and source are credited. 